\title{
Ascites Secondary to Compression of the Caudal Vena Cava by Liver Abscesses in a Cow
}

\author{
Braun $\mathrm{U}^{*}$, Stettler $\mathrm{M}^{1}$, Schramm $\mathrm{S}^{1}$ and Hilbe $\mathrm{M}^{2}$ \\ ${ }^{1}$ Department of Farm Animals, Vetsuisse Faculty, University of Zurich, Zurich, Switzerland \\ ${ }^{2}$ Institute of Veterinary Pathology, Vetsuisse Faculty, University of Zurich, Zurich, Switzerland
}

${ }^{*}$ Corresponding author: Braun U, Department of Farm Animals, Vetsuisse Faculty, University of Zurich, Zurich, Switzerland, E-mail: ubraun@vetclinics.uzh.ch

Citation: Braun U, Stettler M, Schramm S, Hilbe M (2016) Ascites Secondary to Compression of the Caudal Vena Cava by Liver Abscesses in a Cow. J Vet Sci Anim Husb 4(1): 105. doi: 10.15744/2348-9790.4.105

Received Date: October 29, 2015 Accepted Date: January 19, 2016 Published Date: January 20, 2016

\begin{abstract}
Background: Ascites due to thrombosis of the caudal vena cava is relatively seldom in cattle. To our knowledge, there have been no reports of ascites secondary to compression of the caudal vena cava by liver abscesses. This case report describes the findings in a 3.7-year-old Brown Swiss cow with this disease.

Case presentation: The cow had a distended, pear-shaped abdomen. Ultrasonography of the abdomen showed a massive accumulation of hypoechoic fluid and dilatation of the caudal vena cava. A tentative diagnosis of thrombosis of the caudal vena cava was made, and because of a poor prognosis, the cow was slaughtered. Incision of the abdominal wall released approximately 100 litres of yellow, clear, non-malodorous fluid from the peritoneal cavity. The liver was markedly enlarged, and two abscesses, approximately $10 \mathrm{~cm}$ in diameter, were situated immediately adjacent to the caudal vena cava causing compression of the vein. No microbiology culture was done. The final diagnosis was ascites secondary to compression of the caudal vena cava by two liver abscesses and secondary hepatic fibrosis.

Conclusion: This report suggests that compression of the caudal vena cava by liver abscesses should be included in the list of differential diagnosis of conditions associated with ascites and dilatation of the caudal vena in cattle.

Keywords: Cattle; Ascites; Liver abscess; Caudal vena cava; Compression
\end{abstract}

\section{Background}

Ascites is excessive accumulation of fluid in the peritoneal cavity. The ascites fluid can be characterised as inflammatory, noninflammatory, chylous, urine-like, haemorrhagic or bilious [1]. In cattle, ascites fluid is usually non-inflammatory and associated with vascular congestion due to chronic right-sided heart failure, a mediastinal mass, chronic liver or kidney disease, ileus of the small intestines, enteropathies, peritoneal tumours or thrombosis of the caudal vena cava [1]. There are several reports on ascites associated with thrombosis of the caudal vena cava in cattle [2-5], but to the authors' knowledge, there are no reports on ascites secondary to compression of this vein. This case report describes the clinical, ultrasonographic and pathological findings in a 3.7-year-old Brown Swiss cow, which was five months pregnant and had ascites secondary to compression of the caudal vena cava by liver abscesses.

\section{Case presentation}

For several days before referral to our clinic, the cow had a marked decrease in appetite and faecal output and progressive distension of the abdomen. On admission, the cow was in poor general health, had a marked decrease in appetite and a pear-shaped abdomen (Figure 1). The rectal temperature was $38.5^{\circ} \mathrm{C}$, the heart rate $68 \mathrm{bpm}$ and the respiratory rate 28 breaths per min. Rumen motility was severely decreased, the rumen was relatively full and there was no distinct layering of rumen contents. Tests for reticular foreign bodies and swinging and percussion auscultation on both sides of the abdomen were negative. Intestinal motility was markedly decreased, and the cow passed small amounts of dark, watery, malodorous faeces. The results of a urine test strip (Combur'-Test, Roche, Basel) were unremarkable. An increased volume of peritoneal fluid was suspected based on sloshing felt during transrectal palpation. 


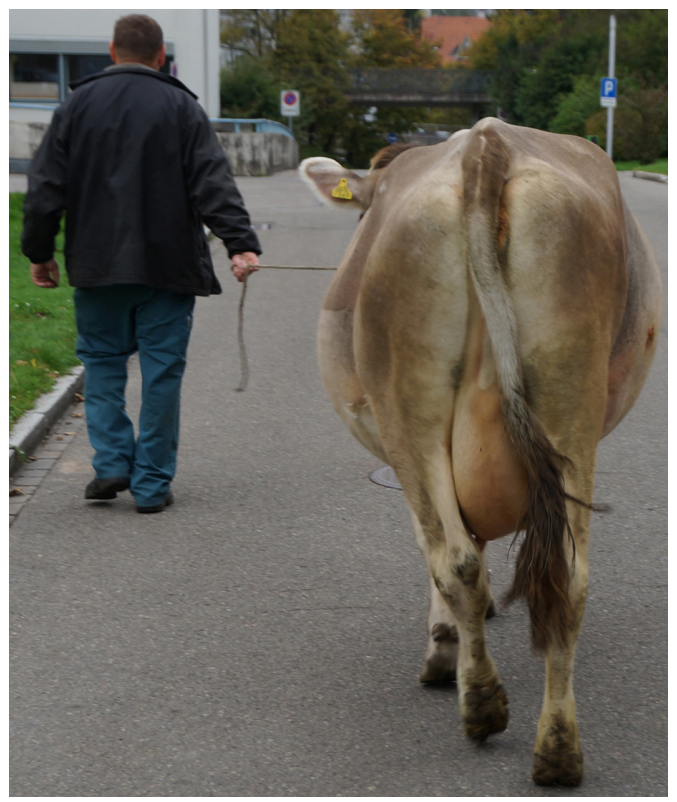

Figure 1: Pear-shaped abdomen in a cow with ascites. Photo showing a pear-shaped abdomen in a BrownSwiss cow with ascites due to compression of the caudal vena cava by two liver abscesses

The results of haematological and serum biochemical analyses showed haemoconcentration, increase in $\gamma$-GT activity, azotaemia, hypocalcaemia and metabolic acidosis (Table 1).

\begin{tabular}{|c|c|c|}
\hline Variable & Cow & Normal range \\
\hline Haematocrit $(\%)$ & 38 & $33-36$ \\
\hline$\gamma$-GT $(\mathrm{U} / \mathrm{l})$ & 56 & $15-25$ \\
\hline Urea $(\mathrm{mmol} / \mathrm{l})$ & 7.7 & $3.5-6.5$ \\
\hline Calcium $(\mathrm{mmol} / \mathrm{l})$ & 2.1 & $2.3-2.6$ \\
\hline Venous blood pH & 7.36 & $7.40-7.50$ \\
\hline Bicarbonate $(\mathrm{mmol} / \mathrm{l})$ & 21.1 & $20-30$ \\
\hline Base excess $(\mathrm{mmol} / \mathrm{l})$ & -3.1 & -2 to +2 \\
\hline
\end{tabular}

Table 1: Selected haematological and biochemical results and venous blood gas analysis in a cow with ascites secondary to compression of the caudal vena cava by liver abscesses

Transcutaneous ultrasonography was performed using a $5.0 \mathrm{MHz}$ convex transducer. It showed a massive amount of hypoechoic fluid in the peritoneal cavity, and the reticulum (Figure 2), intestines (Figure 3) and liver (Figure 4) were displaced dorsally by the ascites fluid. The liver parenchyma appeared heterogeneous and hyperdense on ultrasonograms. The caudal vena cava was circular and dilated in cross-section (Figure 5) and did not have a normal triangular shape [6]. The gallbladder wall was thicker than normal because of oedema (Figure 4). Ultrasound-guided abdominocentesis yielded yellow, clear, non-malodorous fluid with a specific gravity of 1.034 (reference interval < 1.015), a protein concentration of $46 \mathrm{~g} / \mathrm{l}$ (reference interval $<30 \mathrm{~g} / \mathrm{l}$ ), urea concentration of 7.5 $\mathrm{mmol} / \mathrm{l}$ (reference interval similar to that of blood) and creatinine concentration of $94.3 \mu \mathrm{mol} / \mathrm{l}$ (reference interval similar to that of blood). Cytological evaluation of the abdominal fluid showed a few erythrocytes, leukocytes and macrophages, and was classified as a modified transudate. Based on all the findings, a tentative diagnosis of non-inflammatory ascites secondary to thrombosis of the caudal vena cava was made. The cow was slaughtered because of a poor prognosis, and a postmortem examination was carried out. Approximately 100 litres of clear, non-malodorous fluid escaped from the abdomen when the abdominal wall was incised (Figure 6). The liver was markedly increased in size and firmer than normal and had a bumpy surface. Two abscesses with a diameter of approximately $10 \mathrm{~cm}$ were located immediately adjacent to the caudal vena cava and compressed it (Figure 7,8 ). There was no thrombus in the caudal vena cava (Figure 9). Histopathology of the liver parenchyma revealed a diffuse fibrosis, which was especially severe around the centrolobular veins and was often forming fibrous bridges between the periportal spaces (bridging fibrosis). Hepatocytes and hepatic lobules were severely atrophic and midzonal sinusoids were heavily congested and dilated (severe hepatic chronic congestion). Portal tracts were characterized by severe bile duct proliferation and multiplication of arterioles. Several vessel walls were moderately thickend and centrolobular veins were often dilated. The final diagnosis was ascites attributable to compression of the caudal vena cava by two liver abscesses and secondary hepatic fibrosis. 


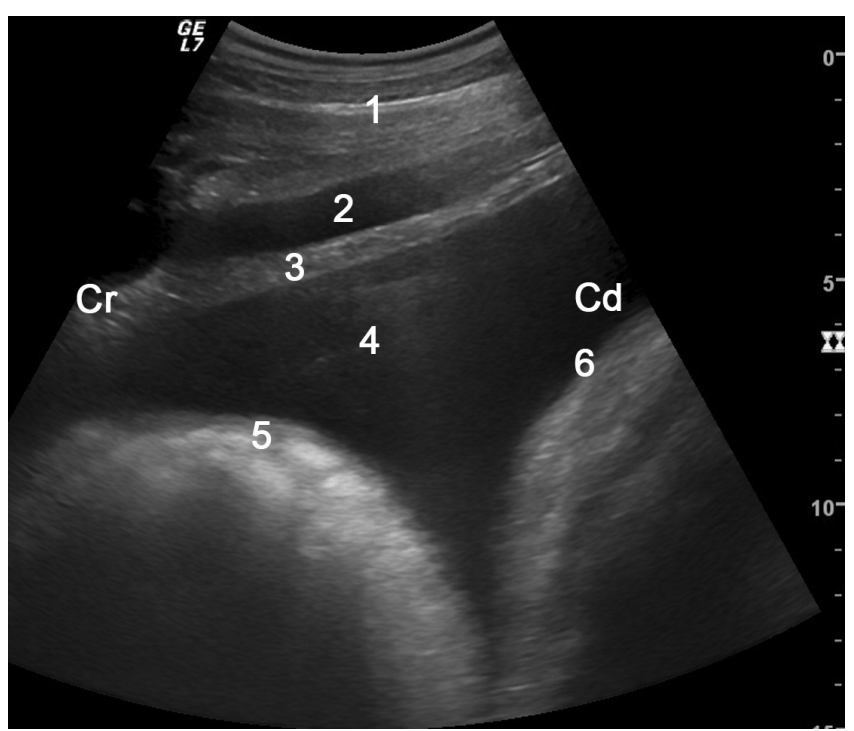

Figure 2: Ultrasonogram of the reticular region. Ultrasonogram of the reticular region of a cow with ascites due to compression of the caudal vena cava by two liver abscesses, imaged from the sternal part of the ventral abdomen. The reticulum is displaced dorsally by anechoic ascites fluid. 1 Ventral abdominal wall, 2 Musculophrenic vein, 3 Diaphragm, 4 Ascites fluid, 5 Reticulum, 6 Anterior dorsal blind sac of the rumen, Cr Cranial, Cd Caudal

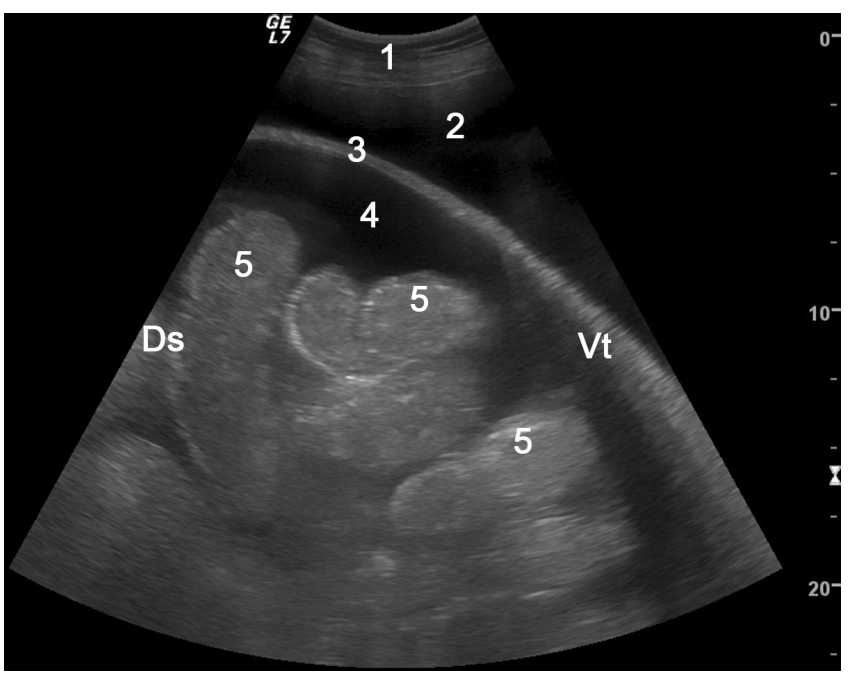

Figure 3: Ultrasonogram of ascites. Ultrasonogram of ascites in a cow with compression of the caudal vena cava by two liver abscesses, imaged from the right flank. Loops of small intestines are displaced dorsally by anechoic ascites fluid. 1 Lateral abdominal wall, 2 Extraomental ascites fluid, 3 Greater omentum, 4 Intraomental ascites fluid, 5 Small intestines, Ds Dorsal, Vt Ventral

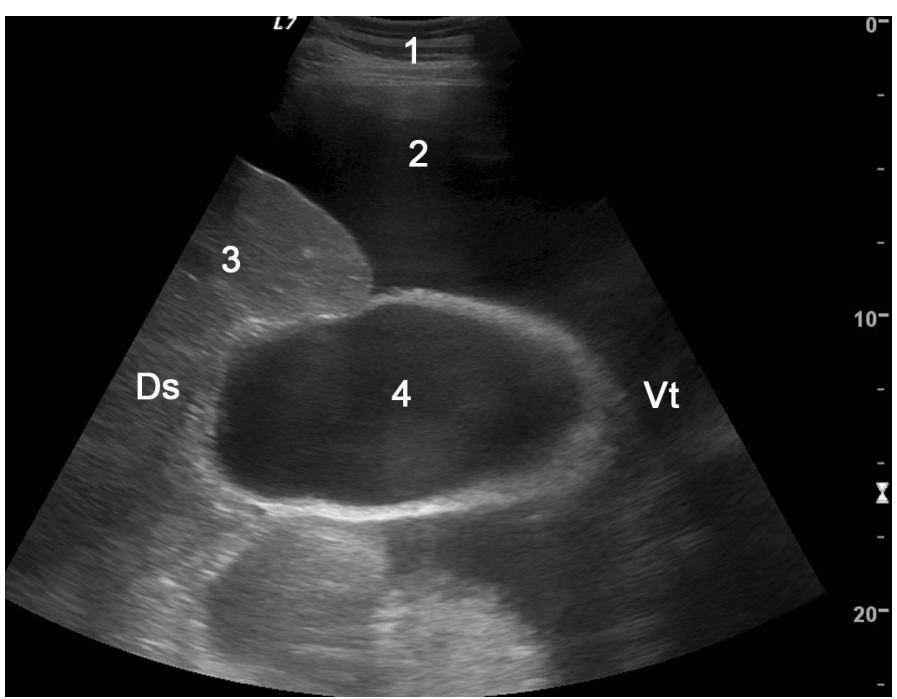

Figure 4: Ultrasonogram of the liver and gallbladder. Ultrasonogram of the liver and gallbladder of a cow with ascites due to compression of the caudal vena cava by two liver abscesses, imaged from the $10^{\text {th }}$ intercostal space on the right side. The liver and the gallbladder are displaced from the abdominal wall by anechoic ascites fluid. The wall of the gallbladder appears thicker than normal because of oedema (congestion). 1 Lateral abdominal wall, 2 Ascites fluid, 3 Liver, 4 Gallbladder, Ds Dorsal, Vt Ventral 


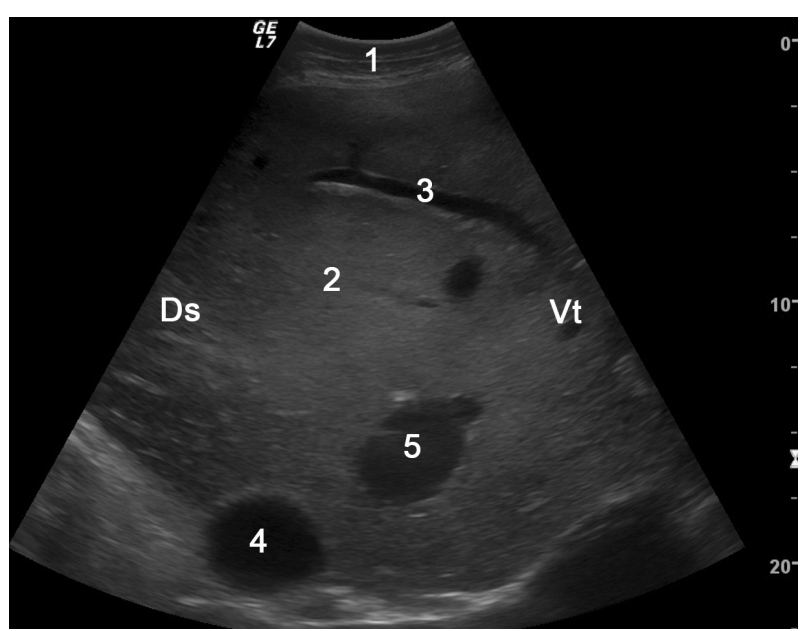

Figure 5: Ultrasonogram of the caudal vena cava. Ultrasonogram of the caudal vena cava in a cow with compression of the caudal vena cava by two liver abscesses, imaged from the $11^{\text {th }}$ intercostal space on the right side. The caudal vena cava, which normally is triangular in cross-section, is round because of congestion and dilation. 1 Lateral abdominal wall, 2 Liver, 3 Hepatic vein, 4 Caudal vena cava, 5 Right hepatic vein, Ds Dorsal, Vt Ventral

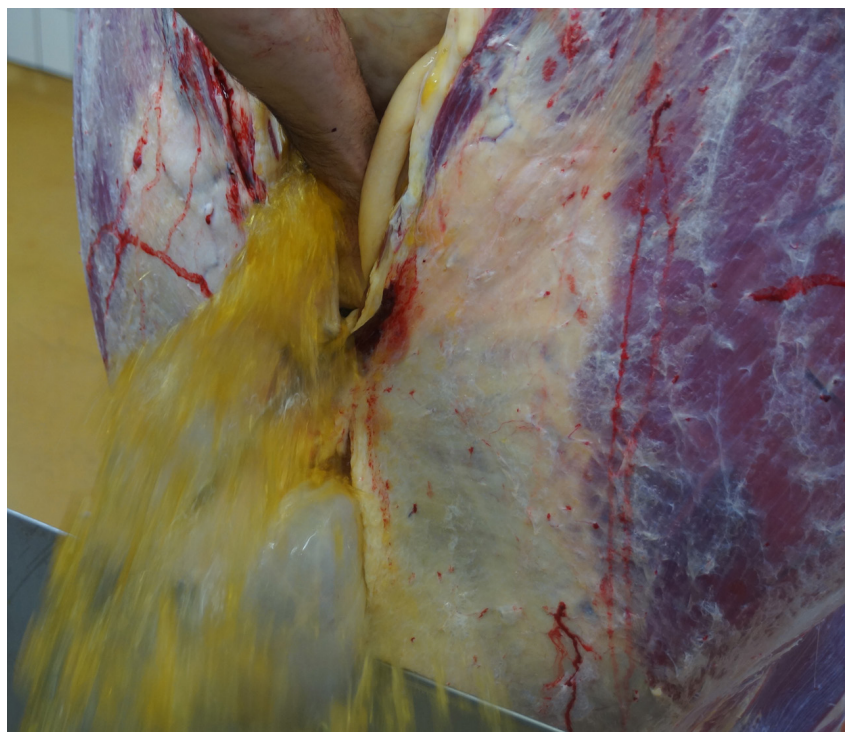

Figure 6: Yellow ascites fluid escapes from the peritoneal cavity. A large volume of yellow ascites fluid escapes from the peritoneal cavity after incision of the abdominal wall during postmortem examination of a Brown-Swiss cow with compression of the caudal vena cava by two liver abscesses

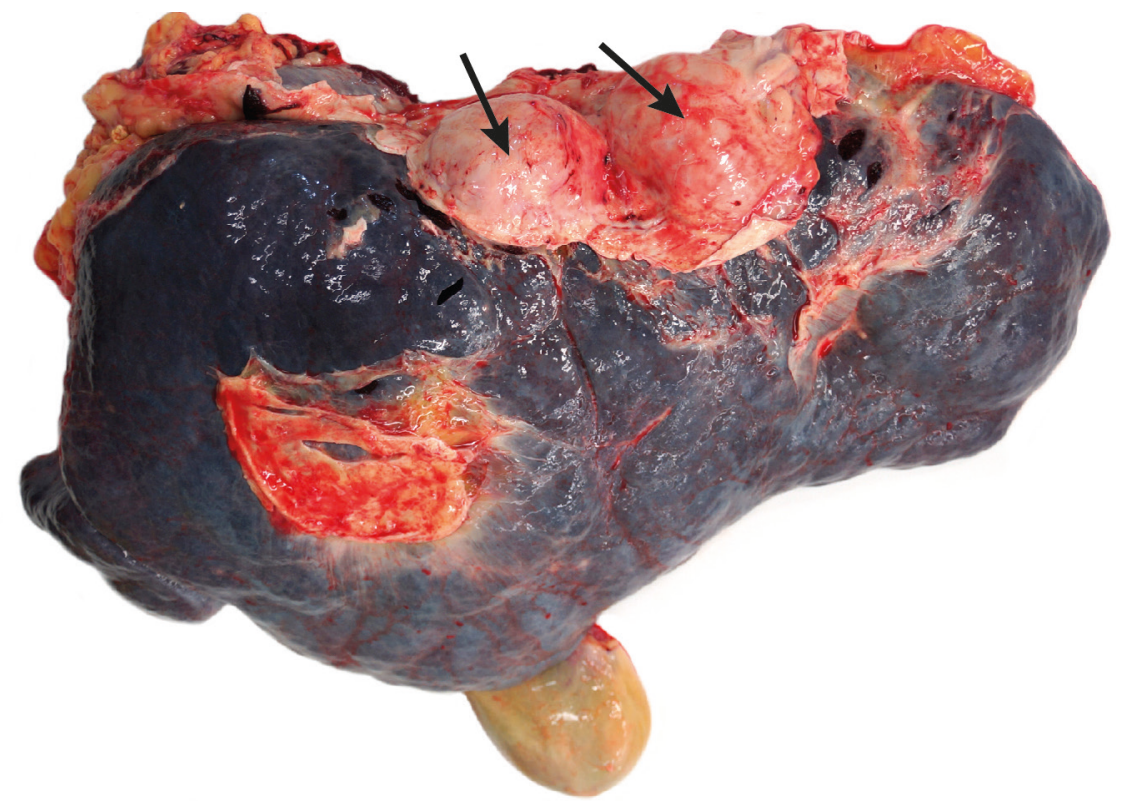

Figure 7: Liver with two abscesses. The diaphragmatic fascia of the liver of a Brown-Swiss cow with two abscesses (arrows) in the upper margin of the liver and immediately adjacent to the caudal vena cava. The liver is whitish-grey and enlarged because of congestion of the caudal vena cava 


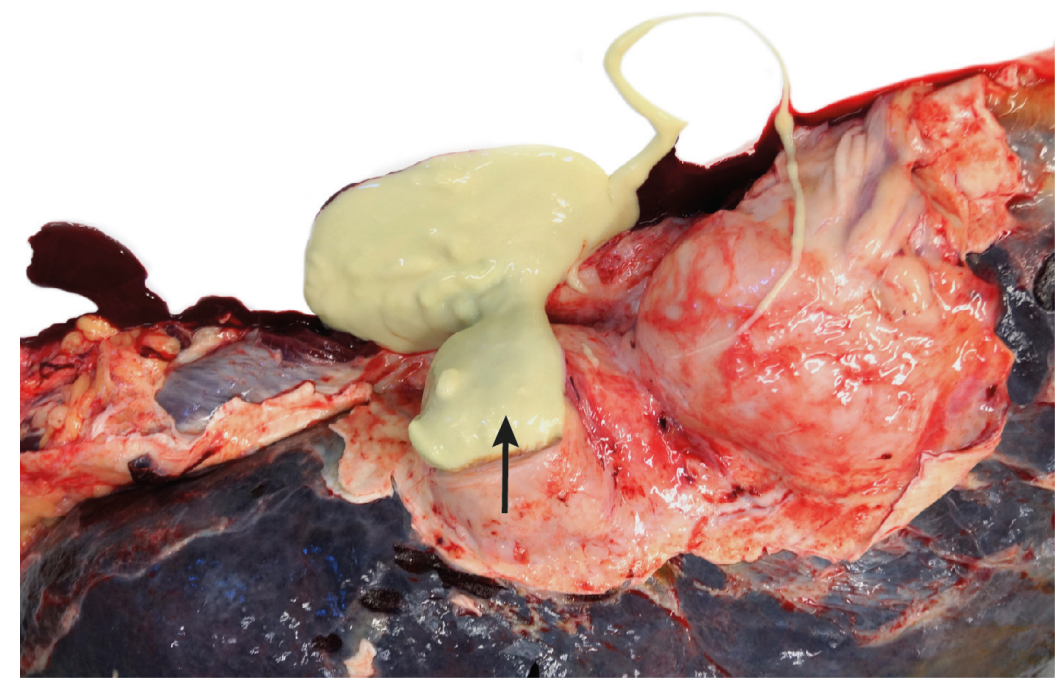

Figure 8: Pus oozes from an incised liver abscess. Yellow viscous pus (arrow) oozes from an incised liver abscess that was compressing the caudal vena cava in a Brown-Swiss cow

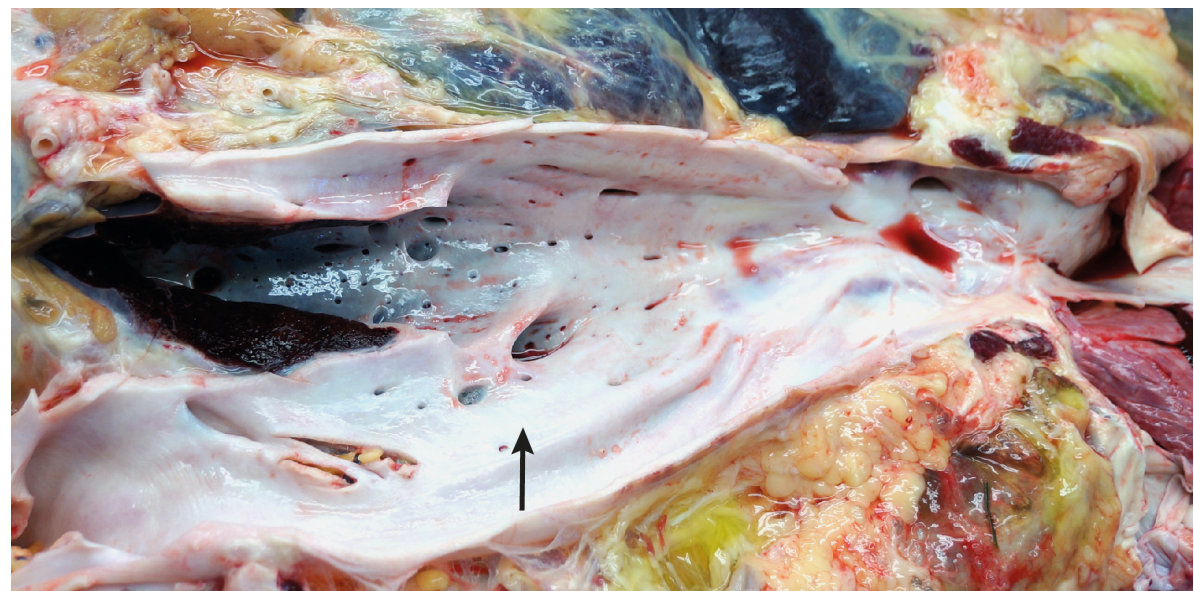

Figure 9: Opened caudal vena. The caudal vena cava (arrow) of a Brown-Swiss cow with compression of the vein by two liver abscesses. The incised and opened caudal vena cava has no macroscopic abnormalities, such as a thrombus

The causes of ascites and the diagnostic work-up of cattle with ascites were recently described in detail [1]. Ultrasonography, abdominocentesis and examination of peritoneal fluid are critical components for determining the aetiology of the problem. Inflammatory and non-inflammatory conditions can be differentiated by peritoneal fluid analysis. Uroperitoneum is diagnosed when the creatinine concentration of peritoneal fluid is higher than that of serum, and an increased concentration of bilirubin in peritoneal fluid usually indicates bile peritonitis. Rupture of a tumour or blood vessel results in haemorrhagic peritoneal fluid, and peritoneal fluid that appears milky and has a high lymphocyte count may indicate chyloabdomen. The most important finding in this case study, other than the massive accumulation of peritoneal fluid, was the change in shape of the caudal vena cava in cross-section. The caudal vena cava normally appears triangular in cross-section [6], but becomes oval to circular with congestion of the vein. Changes in the shape of the vein are of greater diagnostic importance than an increase in the diameter of the vein [7]. Congestion of the caudal vena cava occurs with right-sided heart failure and with obstruction or compression of the vein. In cattle with right-sided heart failure, there is also congestion of the jugular veins, which did not occur in the present case. Our tentative diagnosis of thrombosis of the caudal vena cava appeared to be the most plausible cause because it occurs relatively often in cattle [2-4,7-9]. However, in these cases, a thrombus can rarely be seen via ultrasonography [8-10] because most are located in the part of the caudal vena cava that is obscured by the lungs. An outstanding yet time-consuming method for identifying a thrombus in the caudal vena cava is intraabdominal ultrasonography of the vein through a right-flank laparotomy [11]. Our tentative diagnosis was proved incorrect during postmortem examination, which revealed compression of the caudal vena cava by two liver abscesses. Unfortunately, ultrasonography could not be used to visualize the abscesses because they were located in a part of the liver obscured by the lungs. It is highly likely that a correct diagnosis would have been possible using intraabdominal ultrasonography [11]. The liver abscesses were immediately adjacent to the caudal vena cava and thus led to compression and subsequent congestion of the vein. Liver abscesses are the most common cause of thrombosis of the caudal vena cava in cattle [12-18] and, similar to our case, are situated immediately adjacent to the vein. However, liver abscesses usually rupture into the caudal vena cava and form a fibrinous thrombus attached to the intima, which partially or completely obstructs the lumen of the vein. This did not occur in our case. 
Severe ascites usually is a sequel to increased hydrostatic and decreased oncotic pressure. In the case described in this report, increased hydrostatic pressure in the caudal vena cava was caused by an abscess that compressed the vein and impaired blood flow to the heart, and the decreased oncotic pressure was the result of liver fibrosis caused by congestion.

\section{Conclusion}

In conclusion, the change in the cross-sectional shape of the caudal vena cava from triangular to circular or oval on ultrasonography and the features found through the necropsy suggest that the ascites was caused by compression performed by the abscess and the secondary hepatic fibrosis.

\section{Author's contributions}

Ueli Braun prepared the manuscript and supervised the clinical and ultrasonographic examination, Manuela Stettler and Stephanie Schramm examined the heifer, postmortem examination was performed by Monika Hilbe. All authors have read and approved the manuscript.

\section{Acknowledgements}

The authors thank Dr Rainer Nussbaumer for referring the cow to our clinic, the technicians of the Medical Laboratory for the haematological and biochemical analyses and the animal assistants for looking after the cow.

\section{References}

1. Braun U (2016) Ascites in cattle - Ultrasonographic findings and diagnosis. Vet Clin North Am Food Anim Pract. 32: In press.

2. Braun U, Schefer U, Gerber D, Föhn J (1992) Ultrasonographic findings in a cow with ascites due to thrombosis of the caudal vena cava. Schweiz Arch Tierheilkd 134: 235-41.

3. Braun U, Schweizer G, Wehbrink D, Müller R, Hilbe M (2005) Ultraschallbefunde bei einem Rind mit Aszites infolge Thrombose der Vena cava caudalis [Ultrasonographic findings in a heifer with ascites due to thrombosis of the caudal vena cava]. Tierärztliche Praxis Großtiere 33: 389-94.

4. Braun U, Feller B, Trachsel D, Rütten M, Augsburger H, et al. (2007) Lungenabszess, Pleuraerguss und Aszites bei einem Rind mit Vena-cava-caudalis-Thrombose [Abscess, pleural effusion and ascites in a heifer with vena cava caudalis thrombosis]. Dtsch tierärztl Wschr 114: 165-70.

5. Braun U (2008) Clinical findings and diagnosis of thrombosis of the caudal vena cava in cattle. Vet J 175: 118-25.

6. Braun U (2009) Ultrasonography of the liver in cattle. Vet Clin North Am Food Anim Pract 25: 591-609.

7. Braun U, Flückiger M, Feige K, Pospischil A (2002) Diagnosis by ultrasonography of congestion of the caudal vena cava secondary to thrombosis in 12 cows. Vet Rec 150: 209-13.

8. Braun U, Salis F, Gerspach C (2003) Sonographischer Nachweis eines echogenen Thrombus in der Vena cava caudalis bei einer Kuh [Sonographic detection of an echogenic thrombus in the vena cava caudalis in a cow]. Schweiz Arch Tierheilkd 145: 340-1.

9. Mohamed T, Sato H, Kurosawa T, Oikawa S (2004) Ultrasonographic localisation of thrombi in the caudal vena cava and hepatic veins in a heifer. Vet J 168: 103-6.

10. Simpson KM, Streeter RN, Cramer S, Lamm CG, Love BC (2012) Caudal vena caval thrombosis following treatment of deep digital sepsis. Can Vet J 53: 182-6.

11. Sigrist I, Francoz D, Leclère M, Buczinski S (2008) Antemortem diagnosis of caudal vena cava thrombosis in 2 cows. J Vet Intern Med 22: 684-6.

12. Rubarth S (1960) Hepatic and subphrenic abscesses in cattle with rupture into vena cava caudalis. Acta Vet Scand 1: $363-82$.

13. Stöber M (1966) Pyogene Thrombosen der Vena cava caudalis beim Rind [Pyogenic thrombosis of the inferior vena cava in cattle]. Schweiz Arch Tierheilk 108: 613-21.

14. Selman IE, Wiseman A, Petrie L, Pirie HM, Breeze RG (1974) A respiratory syndrome in cattle resulting from thrombosis of the posterior vena cava. Vet Rec 94: 459-66.

15. Rebhun WC, Rendano VT, Dill SG, King JM, Pearson EG (1980) Caudal vena caval thrombosis in four cattle with acute dyspnea. J Am Vet Med Assoc 176: 1366-9.

16. Ikawa H, Narushima T, Kohno T (1987) Bacteriology of caudal vena caval thrombosis in slaughter cattle. Vet Rec 120: 184-6.

17. Mills LL, Pace LW (1990) Caudal vena caval thrombosis in a cow. J Am Vet Med Assoc 196: 1294-6.

18. Radostits OM, Gay CC, Hinchcliff KW, Constable PD (2007) Caudal vena caval thrombosis (posterior vena caval thrombosis) and embolic pneumonia in cattle. In: Veterinary Medicine. A Textbook of the Diseases of Cattle, Horses, Sheep, Pigs, and Goats (10 ${ }^{\text {th }}$ Edn). Saunders Elsevier Publisher, USA. 516-7. 


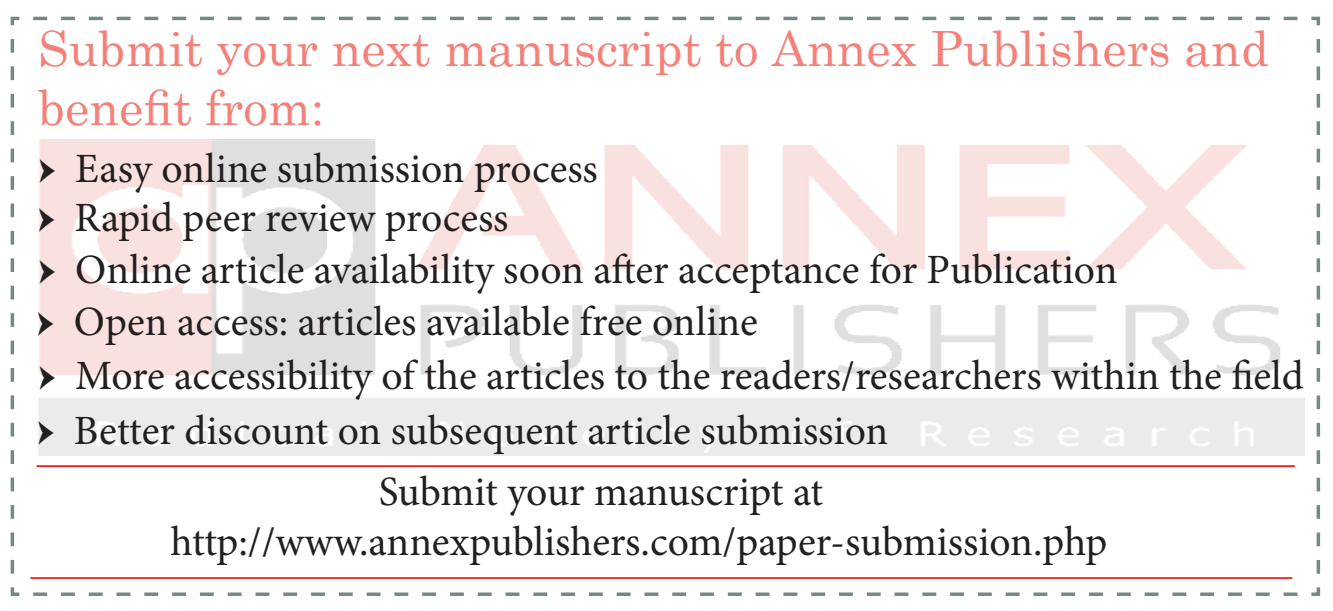

